\title{
Research on the Developing Environment of Management Consulting Industry of Liaoning Province
}

\author{
CHEN Jing ${ }^{a}$, LIU Hong-liang ${ }^{b}$
}

School of Economy and Management of Shenyang Aerospace University, Shenyang 110136, China

a08176@sina.com, b342071425@qq.com

\author{
Keywords: Liaoning Province; Management Consulting; Developing Actuality; Survival \\ Environment
}

\begin{abstract}
Beginning with the origin of management consulting, The development history of management consulting was introduced, the developing actuality of the management consulting enterprises of Liaoning province was analyzed from the data, type, and area distribution, And then the survival environment of management consulting industry of Liaoning province was analyzed from law and policy, economy, market demand and cultural which provided the first hand information to draw up the developing policy for management consulting Industry of Liaoning province.
\end{abstract}

\section{Overview of Management Consulting}

In our country, Consulting and advisory phenomenon has a long history, MenKes in the slave society, the staff officers in the feudal society had started to provide advice.[1] In the 1920s, engineering consulting companies appeared in the British, which developed consulting about project construction. Consulting activity began to change form individuals to institutions. The earliest management consulting appeared in the United States in 1870-1914, which mainly helped manufacturing enterprises improve production efficiency and work efficiency. After the Second World War, the world economy developed rapidly. Some new technologies and new methods which were developed in the war were introduced into the enterprise management practice by some scholars and consulting institutions, which have greatly enhanced the production and management efficiency of enterprises. In 21st century, due to the application of the information technology and so on, the social and economic structure had changed greatly..

\section{Development Status of the Management Consulting of Liaoning}

Year-to-date August 2008, the management consulting enterprises in Liaoning province totaled to 832 which were registered, the registered capital was more than two hundred million yuan, and the employees were more than five thousand persons, such as table 1.

From table 1, we can draw the conclusion: before 2001 there were 44 management consulting enterprises in Liaoning province, but only 9 of them were about management. During 2002 2007, the management consulting enterprises of Liaoning developed very rapidly, 686 management consulting enterprises were registered during this period, which occupied $82.45 \%$ of the all registered management consulting enterprises in Liaoning, corresponding with the rapid economic development in our country at the same time. By 2008, due to the influence of international financial crisis, China's economy growth rate had slowed down, and the registered management consulting enterprises were only 102 at the same time. So can draw the conclusion that the development of the management consulting enterprises accompanied by the development of the economy. 
Table 1 Management consulting enterprise sheets of Liaoning

\begin{tabular}{|c|c|c|c|c|c|c|}
\hline $\begin{array}{c}\text { Consulting } \\
\text { types } \\
\text { Registered time }\end{array}$ & Management & Marketing & Financial & $\begin{array}{c}\text { Human } \\
\text { and others }\end{array}$ & Investment & SUM \\
\hline 2001 and before & $\mathbf{9}$ & $\mathbf{2}$ & $\mathbf{5}$ & $\mathbf{4}$ & $\mathbf{2 4}$ & $\mathbf{4 4}$ \\
\hline $2002-2004$ & $\mathbf{1 0 8}$ & $\mathbf{1 7}$ & $\mathbf{8 4}$ & $\mathbf{9}$ & $\mathbf{6 0}$ & $\mathbf{2 7 8}$ \\
\hline $2004-2006$ & $\mathbf{5 9}$ & $\mathbf{1 9}$ & $\mathbf{5 7}$ & $\mathbf{1 4}$ & $\mathbf{6 1}$ & $\mathbf{2 1 0}$ \\
\hline $2006-2007$ & $\mathbf{4 3}$ & $\mathbf{2 4}$ & $\mathbf{1 3}$ & $\mathbf{2 1}$ & $\mathbf{9 7}$ & $\mathbf{1 9 8}$ \\
\hline $2007-2008$ & $\mathbf{2 1}$ & $\mathbf{6}$ & $\mathbf{1 1}$ & $\mathbf{1 7}$ & $\mathbf{4 7}$ & $\mathbf{1 0 2}$ \\
\hline SUM & $\mathbf{2 4 0}$ & $\mathbf{6 8}$ & $\mathbf{1 7 0}$ & $\mathbf{6 5}$ & $\mathbf{2 8 9}$ & $\mathbf{8 3 2}$ \\
\hline
\end{tabular}

The area distribution of management consulting enterprises very unbalanced in Liaoning, such as Figure 1.

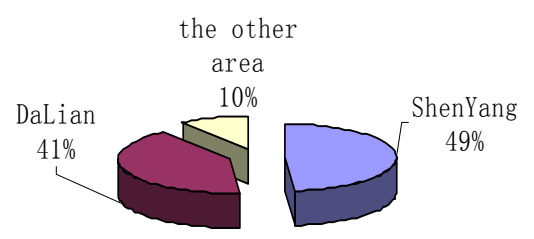

Fig1. the ratio of Management consulting enterprises in different area of LiaoNing

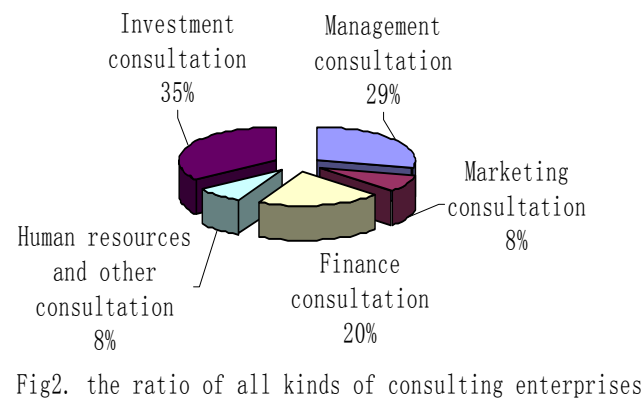

Analyzing on the type of the management consulting companies of Liaoning, Investment consulting companies were the most, totaled to 289, the enterprises which provide comprehensive consulting services such as development strategy, management, and so on, only totaled to 240 . Other such as marketing, finance management, human resource consulting etc. totaled to 68, 170, 65 respectively, that was little proportion. Such as Figure 2.

Although the management consulting industry of Liaoning has developed greatly after being developed more than 10 years based on the analysis above. But huge gap still exists between Liaoning and Beijing, Shanghai and Guangdong. The comparison is shown as table 2.

Table 2 The management consulting enterprises of Beijing, Shanghai, Guangdong and Liaoning

\begin{tabular}{|c|c|c|c|c|c|c|}
\hline & $\begin{array}{c}2001 \\
\text { Area }\end{array}$ & $2002-2004$ & $2004-2006$ & $2006-2007$ & $2007-2008$ & SUM \\
\hline Beijing & $\mathbf{5 5 6}$ & $\mathbf{9 4 4}$ & $\mathbf{6 0 7}$ & $\mathbf{1 2 0 0}$ & $\mathbf{1 4 8}$ & 3455 \\
\hline Shanghai & $\mathbf{3 0 0}$ & $\mathbf{8 9 7}$ & $\mathbf{1 2 7 5}$ & $\mathbf{1 7 3 7}$ & $\mathbf{3 9 6}$ & 4605 \\
\hline Guangdong & $\mathbf{2 9 3}$ & $\mathbf{1 2 5 6}$ & $\mathbf{6 9 3}$ & $\mathbf{4 1 0}$ & $\mathbf{3 5 9}$ & 3011 \\
\hline Liaoning & $\mathbf{4 4}$ & $\mathbf{2 7 8}$ & $\mathbf{2 1 0}$ & $\mathbf{1 9 8}$ & $\mathbf{1 0 2}$ & 832 \\
\hline SUM & 1192 & 3375 & 2793 & 3545 & 1005 & 11902 \\
\hline
\end{tabular}

\section{Analysis on the Survival Environment of Management Consulting Industry of Liaoning Province}

Policy Environment. Early in June 1992, the consulting industry was as one of the prior developing industry in 'the Decision about Speeding up the Development of the Third Industry' issued by the State Council, which provided the basis to develop the consulting industry ${ }^{[1]}$. The State Council issued 'Some Opinions on Speeding up the Development of Service Industry (issued by the State Council No.7 2007)' on March 19, 2007 which put forward to develop the service enterprises related to consulting industry intensively in the article 3, 4 and 6 of the document ${ }^{[2]}$. The State Council, the Department of Industry and Information Industry, the General Government Office of Liaoning Province, Etc. had issued kinds of documents in different time to further accelerate the development of service industry and made the developing direction clearly.

Economy Environment. During the reform and opening up for 30 years, the economy developed rapidly in China with an average annual growth rate of around $10 \%$, became one of the fastest area in 
the world. With the process of reform and opening of China speeding up and deepening as well as joining WTO in 2001, the environment of market and investment and industrial structure, etc. have been optimized further, and have made great achievements in economic construction. The national GDP reached 31 trillion yuan in 2008, ranked third in the world ${ }^{[3]}$. The GDP of Liaoning province reached 13461.57 billion yuan in 2008 .

The financial crisis over all the word beginning with America has brought serious influence to the economy of China since the middle of 2007. The statistics of the small and medium-sized enterprises bureau of national development and reform commission shown that more than 6.7 million of small and medium-sized enterprises bankrupted and more than 20 million workers were fired in the first half year of $2008^{[5]}$.

Market Demand Environment. To analyze the market based on survey data of the Report of the Development of Enterprises of China 2001 which issued by the Union of Enterprises of China: in end of 2000, there were 8000 thousand state-owned industrial enterprises, if more than 1/3 of them need management consulting, there would be 2400 thousand enterprises; also there were about 3000 thousand private enterprises, if $20 \%$ of them need management consulting, there would be 600 thousand enterprises, all totaled to 300 thousand enterprises. If the average demand was $\$ 10,000$ yuan per enterprise, the input of management consulting would be 300 billion yuan ${ }^{[6]}$. The statistical data shown that the turnover was nearly 500 billion yuan ${ }^{[7]}$. The input was far more than 10 thousand yuan to purchase management consulting service per enterprise, and the sum of the enterprises are increasing continually, so the effective demand of management consulting will be far more than \$100 billion dollars in 2010.

Competion Environment. The management consulting enterprises which provide management consulting service can be divided into three types: one type belonged to foreign-owned enterprises. The several world-famous consulting enterprises such as McKinsey, Roland Berger, Accenture, and PWC etc. have established their branches in China at present. The second type belonged to the private enterprises established by whom had experience of studying abroad or had experience of taking office in foreign-owned consulting enterprises such as Adfaith management consulting Co., LTD and so on. The third belonged to the consultancy depending on the resource of economy and management school of university or economy and management institute such as CCID Consulting Co., Ltd. etc.

There were about 100 thousand management consulting enterprises in China, and 832 in Liaoning province in the end of August 2008. The competition between the management consulting enterprises will be fiercer as the well-known foreign management consultancies come into China and the domestic management consultancies increase continuously.

\section{The Peroration}

Along with the establishment of market economy system in China, self-independence of the enterprise management, the management consulting industry from scratch and naive to mature gradually has made great progress. But there is still huge gap in amount or consultation method, or tools, or analysis model, or the completion of the database compared with the foreign advanced management consulting industry. The management consulting industry of Liaoning developed with the development of the management consulting industry of China, but huge gap still exits compared with Beijing, Shanghai, Guangdong in which the management consulting industry developed quickly. To develop the management consulting of Liaoning, we should improve the consciousness of public especially the enterprises, perfect the developmental environment and lay down the developmental policy of management consulting industry, etc. The management consulting industry of Liaoning will gain vast development space on the basis of absorbing the advanced experience of foreign management consulting with the improvement of policy and environment, the opportunity of carrying out the strategy of revitalizing northeast China.

\section{References}


[1] Li Yu, Wang Rui. Analysis on the Impact on National Economy of Consulting. Modern Business.2008 (2), p.45

[2] The State Council.Some Opinions on Speeding up the Development of Service Industry (issued by the State Council, No.7 2007). Mar.19, 2007

[3] National Bureau of Statistics of China. Statistical Yearbook of China (2009). Beijing: Statistics Press of China.2009, p.24

[4] Bureau of Statistics of Liaoning Province. Statistical Yearbook of Liaoning Province (2009). Beijing: Statistics Press of China.2009, p.37

[5] "Bankrupt Tides" Leads to the Hunger of Management Consulting. News of Electronic Consumption In TWICE.2008（18）, p.40

[6] Zen Qing-xue. Analysis on the development status of Management Consulting Industry of China [J]. Information Times.2004（5）, p.116-121

[7] Shi Hong, Liu Jian, Gu Yong-li. the Problem of the Development of Management Consulting Industry of China and the Countermeasure Advice. Market Modernization.2007 (18) , p.26-28 